\title{
An Analysis of ROI of Taiwan's Stock Market: A Case Study in Light of the Chinese Tradition of Store in Winter
}

\author{
Tzu-Yi Yang ${ }^{1}$, Yu-Tai Yang ${ }^{2}$, Jau-Rong Chen ${ }^{3}$ \\ ${ }^{1}$ Department of Business and Management, Ming Chi University of Technology, New Taipei City, Taiwan. \\ ${ }^{2}$ Department of Aeronautical and Opto-Mechatronic Engineering, Vanung University, Taoyuan, Taiwan. \\ ${ }^{3}$ Department of Business and Management, Ming Chi University of Technology, New Taipei City, Taiwan. \\ Correspondence: Tzu-Yi Yang, Department of Business and Management Ming Chi University of Technology, New \\ Taipei City 24301, Taiwan.
}

Received: December 29, 2015

Accepted: January 12, 2016 Available online: January 15, 2016

doi:10.11114/aef.v3i1.1307

URL: http://dx.doi.org/10.11114/aef.v3i1.1307

\begin{abstract}
There is a Chinese saying that goes "plough in spring, hoe in summer, harvest in autumn, and store in winter", which reflects the traditional farming practice of Taiwanese in response to the change of seasons and the ancient annual work-rest pattern of Chinese farmers. This lifestyle of Chinese, however, might be different from that of foreigners. In light of this, this study is carried out based on "Are there any regular variations in the Taiwan stock market: a case study of Taiwan stock exchange capitalization weighted stock Index (TAIEX)", a study by Yang and Yang (2015), in order to determine whether this Chinese idea has rendered Taiwan's stock market any underlying characteristic which is different from other countries' stock markets in terms of investment activities. The results do reveal a regular variation pattern of Taiwan's stock market. In the study, the seasonal change of traditional Chinese farming work-rest schedule is investigated in conjunction with the seasonal variation of Taiwan's stock market. The results reveal that the ROI of Taiwan's stock market tends to be most significant in winter, i.e. there is a Winter Effect. The study also tries to determine whether this effect fits the January Effect in foreign countries. The results suggest the existence of a December Effect in ROI of Taiwan's stock market.
\end{abstract}

Keywords: Effect, Stock market, Taiwan, and OLS

JEL Codes: C2, G1

\section{Introduction}

The liberalization and internationalization of Taiwan's economy in recent years are accompanied by the financial deregulation of many countries and the merger and acquisition of financial institutions in response to the increase of trade between countries and for the purpose of promoting trade. The business scope of Taiwan's financial system as a whole covers investment consultancy, investment trust, financial instruments, property insurance, life insurance, notes, securities, banking, and assets management. In Taiwan, the financial industry is divided into 3 categories, i.e. securities, banking, and insurance, according to regulations governing the establishment of stockholding companies and Financial Holding Company Act. The increasing trend of mergers and acquisitions among banking, securities, and funding institutions has made them more and more interdependent and as a result the world financial map has experienced drastic change. Money market, as part of the financial market, is the platform for the transaction of short-term (within a year) financial instruments, including treasury bonds, commercial papers, banker's acceptance and negotiable certificates of deposit. Money market also includes repurchase agreement market and interbank call-loan market in addition to short-term bills market. Stock market is a place where stocks are issued and circulated, in other words, issued stocks can be transferred and traded here. Stocks are a kind of quoted securities and one of the instruments with which listed companies can raise money. In Taiwan's stock market, the turnover rate of stocks is high and the majority of stocks issued by manufacturers are in the electronic sector because in the past 20 years the electronic industry has rapidly developed to become the mainstay of Taiwan's industry.

However, the prices of consumer goods in Taiwan have been soaring in recent years in spite of people's salary remains roughly the same. As a result, Taiwanese people are complaining that they can hardly make both ends meet with their salary, and those who managed to maintain a balance between income and expenses are among the best. Therefore many people nowadays want to find extra income to cover the gap by investing in the stock market, dreaming that they could become the next Buffett. But the stock market is too hard to predict. Stock prices go up and down in an unexpected way, and many newcomers in the stock market simply get no return for their hard-earned savings and lose 
their confidence because they are apt to make blunders in investment. As shown in Fig. 1, the TAIEX index had been fluctuating drastically during the period from January 20000 to December 2014. For example, TAIEX index was 9000 points in January 2000 but slumped to about 4800 points in a short period of time because of the impact of the burst of dot-com bubble in Hong Kong (March - June 2000), then it started to go up in October 2000 to 6000 points, and dropped to 5800 points within a month. It is thus evident that the stock market is capricious and hard to predict. Investors are in need of wise investment strategy to be more confident in their trading of stocks.

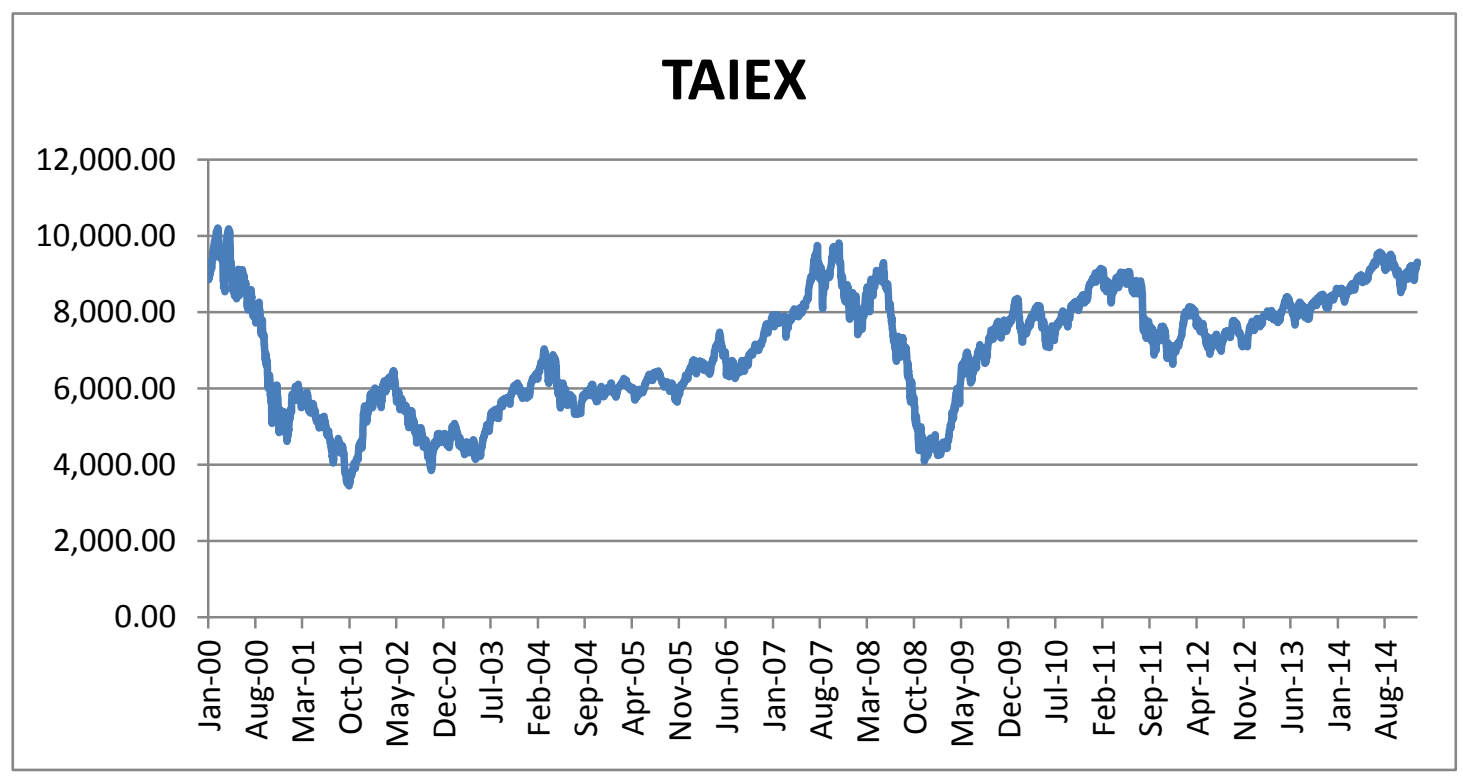

Figure 1. Closing price of TAIEX index (January 2000 - December 2014)

Investors who want to make profits from their investment may be at a loss when it comes to when and how to make correct investment decisions in the stock market, and they all want to know whether there is any criterion or strategy that can help them invest in the stock market more confidently. In the light of this, the purpose of this study is to take advantage of the so-called Winter Effect and determine which month has the highest ROI for the reference of investors. Shieh (2012) argued that there is a close correlation between the variation of interest rate and the fluctuation of stock price. Generally speaking, high interest rate is detrimental to the performance of stock price; low interest rate is beneficial to the performance of stock price. This is because when interest rate is at high level, investors may need a higher ROI to cover the high opportunity cost of their capital, as a result the discount rate they use in the valuation of stocks goes up and the reasonable price of stocks goes down; on the other hand, when the return rate of stocks fails to surpass the return rate of deposit in banks, rational investors would withdraw their money from the stock market and deposit the money in a bank to enjoy the high interest. In such cases, the stock market is destined to go down after losing the driving force. One of the solutions suggested for developing countries like Taiwan in order to overcome the negative effect of high interest rates on the stock market performance is to take advantage of shadow banking industry (Riasi, 2015). It has been proved that shadow banking institutions can provide loans with lower interest rates to corporations and therefore can help them to perform better in the stock market (Riasi, 2015). Having access to lower interest rates will enable the firms to gain competitive advantage in their business (Riasi, 2015). The important point is that the unregulated activities in shadow banking may increase the systemic risk (Schwarcz, 2012; Gennaioli et al, 2013).

Investors who lack a definite direction in their investment are susceptible to investment blunders because nobody can predict stock price. Furthermore, no study is available that demonstrates whether the price fluctuation of a stock in the stock market is affected by the seasonal effect or not. Considering the unpredictability of the direction and amplitude of stock price fluctuation, investors who make investment solely based on their assessment of stock fluctuation are taking high risk without securing a return in proportion to the risk. In this study on Taiwan's stock market, the emphasis is placed on finding out which month in winter has the most significant ROI in light of the Winter Effect. The conclusion will provide useful information to investors, scholars and government sector so that they can fix an investment strategy before making decisions. 


\section{Literature Review}

\subsection{January Effect}

January Effect was originally identified in the United States, where, according to the taxation laws, investors' losses in stock investment may be deducted from their payable income tax. Therefore, many investors may sell out the loss-making small cap stocks in their hands to deduct their payable income tax and may buy them back in the next January. Therefore the stock markets in the United States usually experience a major decline towards the end of the year and a surge in the next January, making the ROI in January higher than other months of the year. A number of research papers on the impact of January Effect on the stock markets of various countries are available at the time of this study. Officer (1975) studied the monthly ROI of The stock markets in Australia for the period from 1958 to 1970. No obvious seasonality was identified on individual stocks in the study, but the phenomenon of seasonality was identified investment portfolios, and the author suggested that such seasonality might be associated with the interest rate variation in individual months.

Rogalski and Tinic (1986) studied 20 investment portfolios of stocks grouped according to their market values and compared the correlation between company scale, before and after risk adjustment in accordance with a single-component market model, and ROI in January, by ANOVA. The study covered a period from 1963 to 1982 and samples were stocks of listed companies in NYSE and AMEX. The study came to a conclusion that the non risk-adjusted return in January was significantly higher than that in other months of the year, so high that it was almost 4 times higher than the month with the second highest return. Scale Effect was observed only in January and February. The risk of investment portfolios consisting of stocks of small cap companies had higher risk in January than other months of the year, whether judged by total risk or systematic risk. In the light of this, the high return of stocks of small cap companies in January might come from the compensation for high risk. Seasonality of return was conspicuous after risk adjustment and January was still the month that had the highest return. The most significant scale effect was seen in January and February.

Chen (1996) tested the January Effect on return (excluding dividend) from high-grade, medium-grade and opportunistic-grade special stocks by OLS and Kruskal-Wallis test in an empirical investigation covering the period from 1927 to 1991. The study results showed January Effect was identified in special stocks of all grades. This effect was different from Scale Effect, which was seen only in small cap stocks and low-grade bonds of ordinary stocks or corporate bonds. The return in January was higher than the total return from all other 11 months of the year, and would increase with the decrease of the grade of the special stocks. According to Siege (1994), the first one who identified January Effect was Don Keim. Based on historical data of stock markets, Don Keim came to the discovery that in January the performance of small cap stocks are always far more superior to large cap stocks. In fact, January was the only month in which the performance of small cap stocks was better than that of large cap stocks over the past 70 years: in the period from 1925 through 1997, the average ROI of small cap stocks in January was $6.2 \%$ while the average ROI of Standard \& Poor's 500 was only $1.6 \%$. This $4.8 \%$ advantage in ROI gained in January by small cap stocks over large cap stocks was larger than the ROI difference between small cap stocks and large cap stocks throughout the whole year.

It can be inferred from the above-mentioned studies on the data available so far that January is the only month in which investors have the biggest chance to make profits. Therefore January Effect can be of reference value to investors. As regards why January Effect has not be noticed by investors or financial experts, in the case of stock markets in the United States, it might be attributed to the fact that most people judge the fluctuation of stock markets according to the performance of Dow Jones Indexes and Standard \& Poor's 500 indexes, both are based on large cap stocks. In fact, the performance of large cap stocks in January is usually quite satisfactory, especially in many foreign countries' stock markets. Large cap stocks in stock markets of the United States, however, are an exception, their performance in January is not the best. Besides, the occurrence of that small cap stocks yielded performance inferior to that of large cap stocks in January became more and more frequent in recent years. Therefore, few people still remember this effect. There are other factors that may also contribute to January Effect, for example, one being that many people have extra income towards the end of a year, such as dividend from a company, or the money from selling their loss-making stocks. These cashes are usually spent in the first week of January on buying stocks. Basically on the first several days at the beginning of a year, ordinary retail investors will buy substantially more than sell, and small cap stocks take up a large percentage in the investment portfolios of retail investors. Shieh (2011) found that the January Effect might be attributed to the fact that the amount of investment made in January are usually larger than that made in other months of the year, this is more evident in small cap stocks than in large cap stocks. Cayman discovered that the return of investment portfolios consisting of small cap stocks was larger than that of investment portfolios consisting of large cap stocks in 1963 1979, and 50\% of the return difference was from January. Some empirical studies argued that it is a phenomenon caused by investors' tax avoidance maneuver, i.e. investors sell their loss-making stocks for real losses, which can be deducted from their payable taxes, then they might invest the money from selling stocks into the stock 
market early next year. As a result, stock prices will rise. Cayman, on the other hand, argued that the return of small cap stocks in January would still be high even if the prices of small cap stocks had not dropped. Besides, January Effect has been identified in stock markets of countries where there is neither income tax levied on revenue from neither stock trading nor tax settlement at the end of the year. In light of this, January Effect is deemed global.

Results of a study by Officer (1975) revealed that, the draw up of stock market might be affected as the result of interest rate variation in individual months; Rogalski and Tinic (1986) and Chen (1996) described that return from stocks in their studies was much higher in January than in other months of the year; Siege (1994) and Shieh (2011) also argued the existence of January Effect. From the above-mentioned literature review, it can be inferred that January Effect does exist in stock market and it is a global effect which boosts the ROI of stock market in January to a level higher than that in any of the other months of the year.

Siege (1994) pointed out if one invested 1 dollar on Dow Jones Indexes in 1890, the money would increase to 197.74 dollars (excluding dividend) by the end of 1996. If the calculation was based on data from Septembers only, then only 26 cents of the investment would remained; if the calculation was based on data from the other 11 months of the years, then the money would increase to 681.92 dollars. It has been proven by studies that the overall ROI performance of investment in stock market in September is extremely poor, and the underlying reason might be that, people's expenditure increases in September because schools open in that month and some people might have to sell their stocks to raise money, as a result, the stock market in September tends to decline. In fact, September is the only month that registers an overall negative ROI over the years.

December Effect, as the name implies, is a periodic effect taking place naturally in December as a whole. In China's monetary fund market, the return in December is much higher than in other months. This happens as a result of that, major commercial banks in China are under the pressure of year-end annual auditing and performance assessment and therefore in larger need of funds. Against this backdrop, the supply of funds usually falls short of demand, giving rise to an increased interest rate in interbank call-loan market as well as the monetary fund market.

According to Fan (2010), the share of corporate transactions of stocks had been increasing year by year in Taiwan's stock market. His study, which took advantage of literature on the impact of overbought/oversold by the 3 major corporate investors on TAIEX index, yielded results that pointed to January Effect or Long Vacation Effect, i.e. the ROI in January or during long vacations tended to be different with that in other months of the year. Keim's (1983) study results revealed that the average return of NYSE and AMEX in January was higher than that in other months of the year during the period from 1963 to 1976; Tong's (1992) empirical results pointed out that January Effect was seen in Taiwan's stock market in 1980. Weng Hong-Lin, Lin Chuan-Yuan recorded the occurrence(s) of abnormal negative ROI in December in bull markets.

According to Lee (1992), the occurrences of abnormal negative ROI in spite of the January Effect had been seen not only in the United States but in other countries as well. But there were also scholars trying to deny the above saying by the application of the Selling of Loss-making Stocks for Tax Avoidance hypothesis in a study on 5 major Asian countries. In that study, it was found in Hong Kong, Taiwan, Singapore and Japan that the return in other individual months was apparently lower than that in January.

Since these countries did not levy capital gains tax, it was therefore evident that the Loss-making Stocks for Tax Avoidance hypothesis only stands for countries that levy capital gains tax, such as the United States. Therefore, this hypothesis applies only to countries that levy capital gains tax, where the investors are fully motivated to sell their loss-making stocks towards the end of a year in order to avoid taxation.

It can be inferred from the study results of the above-mentioned two references that there is indeed the so-called December Effect in stock markets. But depending on the region in which the stock market is located, this effect may be subjected to a time lag which gives rise to varied conclusions on whether the December Effect boosts or drags the ROI of stocks.

\subsection{Weekend Effect}

Weekend Effect, also called Day-of-the-Week Effect, refers to that investors may sell or buy stocks depending on their prediction of what will happen in the coming weekend. Either a substantially increased closing price (good expectation) or a substantially decreased closing price (bad expectation) may be seen on a Friday.

According to Huang (1985), a dissertation entitled the influence of institutional investors and U.S. stock markets on the weekend effect of Taiwan's stock market discussed the TAIEX indexes in 1967-1984 and Economic Daily News indexes in 1978-1984. The study tested the significance of Weekend Effect by t-test and found weekend effect in ROI of stock investment and the average return on Mondays was negative. He proceeded to study whether the findings were caused by market closing effect and found if the transaction day right after a holiday was in the range of Monday to Wednesday, the return on that day would be significantly lower than the return on a corresponding normal transaction 
day; if the transaction day right after a holiday was in the range of Thursday to Friday, the return on that day would be higher than the return on a corresponding normal transaction day, suggesting that market closing could indeed strengthen Weekend Effect. Hawawini and Keim's (1995) study revealed that the performance of global stock markets on Mondays as a whole tended to be poor. The overall ROI of stock market on that weekday was lower than zero, this applied not only to the United States but to Canada, United Kingdom, Germany, France, Japan, Korea and Singapore as well.

A review of the performance of stock markets in the United States revealed that the allegation of Red Friday and Black Monday stands for most transaction days. This phenomenon may be attributed to that, listed companies tends to release negative news of the week in weekend, leading to the so-called black Monday. As for positive news, listed companies tend to release them in transaction hours from Monday through Friday so that their stocks may take on an upward trend. Short-sellers tend to be very cautious when quotations on market are on the rise and seldom go short easily and, even if they do so, they usually take actions near the closing moment. As a result, the market is under the control of long position, giving rise to the so-called Red Friday.

In reference with Day-of-the-Week Effect section of Lee (2009) dissertation Seasonal Regularities and Information Transmissions: Evidences from the U.S. and Chinese Commodity Futures Markets, 6 futures, i.e. copper, aluminum, soybean, corn, cotton and wheat are selected and studied. Empirical results showed most high returns in commodity futures market of the United States were seen on Mondays or Fridays. But in China's commodity futures market, they were seen on Mondays. These results suggest the presence of Day-of-the-Week Effect, though it takes on significantly different appearance on the futures markets in the two countries. Weekend Effect was also seen in stock markets, though on different day of weekend, in the United States and mainland China. We find that futures play an important role in financial market and know that the presence of Weekend Effect in market may have impact on the demand for the materials provided by suppliers.

\subsection{Seasonal Effect}

December Effect refers to that the profit of monetary funds in December may be significantly higher than in other months of the year. The substantial increase of profit in December can boost the price of a monetary fund to a high point.

The presence of Winter Effect can be determined by a review of the descriptions of the monthly variation of TAIEX from 1998 to 2013 provided in Unique Business Weekly (2014). The highest average ROI was 9.6\%, seen in the period from December to March, the coldest months of the winter. Presently TAIEX index is at the level of 9000 points, the above-mentioned ROI means an increase of 800-900 points; such an increase expectation is beckoning indeed. Considering that the stock market has the highest probability to go up in winter (December March), investors should not give up in winter.

In reference with Month-of-the-year effect section of Lee (2009) dissertation Seasonal Regularities and Information Transmissions: Evidences from the U.S. and Chinese Commodity Futures Markets, 8 representative commodity futures, i.e. natural gas, copper, light crude oil, gold, corn, soybean, soybean meal and wheat are selected and studied in this research. Empirical results showed the highest return from natural gas futures market in a year used to be seen in March; the highest return from copper and light crude oil futures market in a year used to be seen in January; the highest return from gold and the rest 4 farming products futures market in a year used to be seen in August - October. The results showed a month-of-the-year effect does exist in these commodity futures market, but the month in which the month-of-the-year effect might be seen varies. For some commodity futures, seasonal factor might be one of the causes that contribute to the month-of-the-year effect. For example, August and October are the harvest season for wheat and corn, respectively, and this seasonality may contribute to seasonal abnormality in futures market of wheat and corn.

According to Kuo (1998) seasonality is not a common phenomenon in financial market, and the seasonality of foreign exchange market seems to be closely related to the seasonality of stock market. Of the months around the turn of a year, November, December, January and February are the months in which abnormalities are most likely be seen on stock market, foreign exchange market, and money market. The seasonality of interest rate and the seasonality of ROI of commercial papers in money market are most consistent, and short-term consistency is higher than long-term consistency; the seasonality of return from stocks is related to empirical trade-off and the quotation trend on market, to be specific, it is more significant in early stage than in late stage, and more significant in long position than in correction phase. Furthermore, Chen (1991) pointed out in his dissertation A study on scale effect and seasonality of Taiwan's stock market that the return of stock seemed to be higher in September throughout the year, and the underlying cause for this phenomenon might be the influence of an increased money supply; the return of stock in October and December was lower in his study mainly because of the impact of a crash of NYSE and a decreased money supply and the levy of income tax. His conclusion was that there was no fixed seasonality seen in the return of Taiwan's stock market and no significant correlation between the seasonality of the return of Taiwan's stock market and company scale. 
In summary, ROI variation takes on different and localized patterns, for example, January Effect for stock markets of the United States and December Effect for the monetary fund market of mainland China. The above literature review reveals that many of the studies used OLS to test their research hypotheses. In the light of this, this study also uses OLS to test its research hypotheses.

\section{Data Description and Study Method}

\subsection{Data Description}

This study aims to explore which month of the months involved in the Winter Effect demonstrated the highest ROI of TAIEX index. The data used in the study are from Taiwan Stock Exchange (TWSE), including index data and turnover volume data of Taiwan's stock market for the period from January 2000 to December 2014, of which the index data are used for calculating the ROI of stock market index according to Formula (I).

$$
\mathrm{SRt}=\frac{S t-S_{t-1}}{s_{t-1}} \times 100
$$

Where $\mathrm{SR}_{\mathrm{t}}=\mathrm{ROI}$ of stock market index on Day $(\mathrm{t}) ; \mathrm{S}_{\mathrm{t}}=\mathrm{Index}$ of stock market on Day $(\mathrm{t}) ; \mathrm{S}_{\mathrm{t}-1}=\mathrm{Index}$ of stock market on Day (t-1)

\subsubsection{Taiwan Stock Exchange (TWSE) Profile}

Taiwan Stock Exchange (TWSE) is a franchise business responsible for promoting the market operation of securities and the development of private companies and organizations in R.O.C. Its establishment includes 15 directors and 3 supervisors, at least one third of whom are appointed by regulatory authorities. TWSE has, since its foundation in 1961, based on the business philosophy of "serving the market wholeheartedly" and abiding by the vision of "activating economy by securities circulation", substantially promoted the economy of R.O.C., and strived to fulfill the two missions of "more secured investment and more convenient funding" by providing enterprises with a perfect funding environment so that they can improve their competitiveness, expand their business territory, create more employment opportunities and by serving the functions of securities dealers administration and market supervision for guaranteed investment rights and benefits; in the meantime, it has also implemented the 3 strategies of "information transparency, fair trade, finance products diversification" to improve market efficiency in response to the needs of investors and listed companies for continuously intensifying and expanding the functions of securities market. TWSE has prepared itself for future challenges and competition by implementing the 4 functions of "innovating products, serving market, engaging allies, and expanding" in line with international trend and in reference with practices of other countries and by taking the opportunities brought about by new mechanisms, new products, new information, new markets, and new competitions.

\subsubsection{Business Scope of Taiwan Stock Exchange (TWSE)}

With a business scope covering transaction (settlement), listing and supervision, TWSE has established 16 departments and a staff of 624 employees for providing the securities market with complete services including pre-listing guidance, post-listing supervision and governance, market order maintenance, transaction system improvement, investor protection, securities dealer service, clearing and settlement operations, prevention of defaults on the market, stock market supervision, and investigation and punishment of unlawful transactions.

\subsection{Study Method}

It can be inferred from the study by Yang and Yang (2015) that the Winter Effect does exist in Taiwan's stock market. The study method of this research is for determining which month of the months involved in the Winter Effect has the highest ROI of TAIEX index. In this study, TAIEX indexes are calculated with daily data. The data used in the study are daily indexes and daily turnover volume of Taiwan's stock market. ROIs of stocks are calculated and Formula (II) is used to find out which month of the months involved in Winter Effect has the most significant ROI of TAIEX index.

$$
\operatorname{SRt}=\beta_{0}+\beta_{1} M_{t}+\beta_{2} D_{-} M+\varepsilon_{t} \quad, t=1,2,3,4 \ldots, n
$$

Where SRt= ROI of stock market index on Day (t); $\mathrm{M}_{\mathrm{t}}$ : turnover volume of stock market on Day (t); D_M refers to a virtual variable of turnover volume of stock market in 3 months(January, February, December); $\beta_{0}, \beta_{1}$ and $\beta_{2}$ are coefficients for the independent variables; $t$ refers to the number of observations.

\section{Empirical Analysis}

In this chapter, Formula (II) is used to test the presence of Month-of-the Year Effect in Taiwan's stock market. According to Chen Deng-Ching's (2012) dissertation, the seasons in Taiwan are defined as follows: Spring: March 1 to May 15; Plum Rain Season: May 16 to June 15; Summer: June 16 to August 31; Autumn: September 1 to November 30; Winter: December 1 to the end of next February. The definition of seasons in this paper is based on Chen's dissertation, 
however, since the concept of plum rain season applies to neither Taiwan's stock market nor international stock markets, days in the plum rain season are allocated to Spring and Summer, and concept of typhoon season is also abandoned because the operation of stock market is not affected by typhoons. It is determined in this study that the months involved in Winter Effect are December, January and February. The data used in the study are the daily data for the study period (January 2000 to December 2014) from Taiwan Economic Journal (1990). The dependent variable (daily ROI of stock market index) and the independent variables (monthly turnover volume and ROI of stock market for December, January and February) are subjected to simple regression model and statistical tools in SPSS20.

\subsection{Definition of Winter and Determination of Months Involved in the Winter Effect}

In Chen's dissertation (2012), a typhoon season (July 1 to October 31) was defined because Taiwan, a country of subtropical island climate located on the Pacific Ocean rim bordering the Eurasia continent where East Asian monsoons prevail, has a precipitation distribution pattern that is affected much by the hydrological seasons of low water season and high water season. This research is to determine the presence of Winter Effect in Taiwan's stock market during period from January 20000 to December 2014 and then identify the month that has the highest turnover volume and ROI from the months of December, January and February.

Table 1. Definitions and days of winter months

\begin{tabular}{lll}
\hline Winter Months & Period & Days \\
\hline December & Dec. $1-$ Dec. 31 & 31 \\
January & Jan. $1-$ Jan. 31 & 31 \\
February & Feb. 1 Feb. 28 or Feb. 29 & 28 or 29 \\
\hline
\end{tabular}

4.2 Descriptive Statistics

In this study, the daily ROI and turnover volume data for the period from January 20000 to December 2014 are summarized and subjected to SPSS 20 to get the maximum values, minimum values, average values and standard deviations of these data. The results show these data vary significantly but all correlation coefficients among the variables are below 1, and this is sufficient to demonstrate that the variables are of low correlation and would not interfere with each other. The calculation results are as shown in Table 2.

Table 2. Descriptive statistics of Month-of-the-Year Effect in Taiwan's stock market

\begin{tabular}{lllll}
\hline $\begin{array}{l}\text { YearlVar. } \\
\text { 2000-2014 }\end{array}$ & Max. Value & Min. Value & Average Value & SD \\
\hline SR & 5.773104602 & -6.513279574 & 0.116663539 & 1.376865534 \\
M & $326,462,532$ & $15,002,513$ & $105,758,839.256$ & $43,709,919.874$ \\
\hline
\end{tabular}

Description: SR denotes daily ROI of stock market index, M denotes daily turnover volume of stock market (in 1000 NT\$). The study covers the period from January 20000 to December 2014 (a total of 857 samples).

\subsection{Regression Analysis}

In this study, data are subjected to test by SPSS 20 using Formula(II) and it is determined that Winter Effect, to be specific, December Effect, is present in Taiwan's stock market index data. The empirical results are as shown in Table 3.

Table 3. Regression analysis of Taiwan's stock market data for identifying Month-of-the-Year Effect

\begin{tabular}{llll}
\hline $\begin{array}{l}\text { No. } \\
\text { Turnover Volume }\end{array}$ & 1 & 2 & 3 \\
\hline MD_1 & 0.104 & & \\
MD_2 & $(-0.366)$ & 0.108 & \\
MD_12 & & $(-1.431)$ & 0.103 \\
R-Squared & & & $(1.735)^{*}$ \\
Observation & 0.013 & 0.015 & 0.016 \\
\hline
\end{tabular}

Description: MD_1 denotes turnover volume in January, MD_2 denotes turnover volume in February, MD_12 denotes turnover volume in December. The dependent variable is daily ROI of stock market index, *,**,***, denote the significance levels of $10 \%, 5 \%$ and $1 \%$, respectively. The study covers the period from January 20000 to December 2014 (a total of 857 samples). 


\section{Conclusion and Suggestions}

In this study, data for the period from 2000 to 2014 are subjected to Formula (II) to identify the influence of Chinese farming seasons on ROI of Taiwan's stock market in light of "plough in spring, hoe in summer, harvest in autumn, and store in winter", a Chinese saying that reflects the traditional Chinese farming seasons and the ancient annual work-rest pattern of Chinese farmers. The study reveals that, of the 4 traditional Chinese farming seasons, winter due to its "Store in Winter" Effect is of higher significance to Taiwan's stock market. This finding is an evidence of the achievement of the application of Chinese work-rest schedule in stock market investment. The study results support Yang (2007) summary of the monthly performance of stock market, which goes "Invest in January to enjoy, February to celebrate the Spring Festival, March and April to read annual financial report, May to get impoverished, June to die, July to hang oneself, August to slip, September to get dull, November to thank giving, December to be joyous when Christmas comes", in short, the period from December to January is the best time when the monthly ROI is most appealing . The result reveals that the performance of Taiwan's stock market is the best during winter (December to February) and the ROI in December is the highest of the year. In other words, December Effect is identified in Taiwan's stock market. The underlying cause for this phenomenon might be that, Taiwan's economy is export-oriented and manufacturers in Taiwan rush to deliver products to the United States and European countries before Christmas and receive payment for the goods after shipment. As a result, the ROI in December is the highest in Taiwan's stock market.

Numerous studies on Taiwan's stock market have led to the discovery of another factor, which is called the election Bull Run, that contributes to the December Effect. According to Cho (2004), the legendary election Bull Run in Taiwan's stock market is by no means groundless. His study revealed the probability of that Taiwan's stock market experiences an abnormal movement of ROI towards the positive side before an election is high. This is true especially after the 1998 election. Taiwan's stock market has experienced an abnormal movement of ROI towards the positive side without exception in every election since then, and this is the so-called election bull run. This study suggests that investors in stock market should take into consideration the influence of an election bull run when making investment decisions. In Taiwan, most elections are held in mid-January. As a result, the stock market may experience an abnormal movement of ROI towards the positive side in such cases. Investors are recommended to take into consideration the influence of an election bull run when making investment decisions.

It can be inferred from empirical results that Taiwan's stock market indeed has a consistently regular variation which is called the December Effect. A number of factors as discussed above have contributed to this effect. Therefore, investors may choose to make investment in stock market in winter. However, it is advisable that they trade strategically and flexibly in order to avoid investment blunders.

\section{References}

Chen, C. R. (1996). January Seasonality in Preferred Stocks, The Financial Review, 31(1), 197-207.

Chen, D. J. (2012). "Extreme changes in the rainfall in Taiwan 1950-2010." Taiwan, National Central University Atheneum.

Chen, M. T. (1991). "Taiwan Stock Market scale and seasonal phenomena." Taiwan, National Cheng Kung University.

Cho, S. C. (2004). “The Empirical Study on the Election Bull Run in Taiwan's Stock Market: 1989-2004” Taiwan, National Cheng Kung University.

Chuang, S. F. (2007). "The Research on January Effect and Chinese Lunar New Year Effect in Taiwan Stock Market Before and After Asian Financial Crisis." Taiwan, National Cheng Kung University.

Fan, K. L. (2010). "The relationship among Institutional Investors" Net buy-sell Differences, the return of market index and the effects of December and January--Example on Taiwan stock market" Taiwan, Nanhua University Atheneum.

Gennaioli, N., Shleifer, A., \& Vishny, R.W. (2013). A model of Shadow banking. The journal of Finance, 68(4), 1331-1363.

Guo, S. M., \& Cho, S. C. (2004). "An Study on Financial Market Seasonality in Taiwan-An Empirical Investigation on Stock Market, Foreign Exchange Market, and Money Market.” Taiwan, National Taiwan University.

Hawawini, G., \& Keim, D. B. (1995). On the predictability of common stock returns: World-wide evidence , Handbooks in Operations Research and Management Science, 9, 497-544.

Huang, J. Y. (1985). "Study on weekend effect of stock-based compensation investment." Taiwan, National Chengchi University.

Lee, I. (1992). Stock market seasonality: Some evidence form the Pacificbasin countries, Journal of Business Finance and Accounting, 19(2), 199-210. 
Lee, K. C. (2009). "Seasonal Regularities and Information Transmissions: Evidences from the U.S. and Chinese Commodity Futures Markets." Taiwan, Feng Chia University Atheneum.

Officer, R. R. (1975). Seasonalities in Australian Capital Markets: Market Efficiency and Empirical Issues, Journal of Financial Economics, 2(1), 29-51.

Riasi, A. (2015). Barriers to international supply chain management in Iranian flower industry. Management Science Letters, 5(4), 363-368.

Riasi, A. (2015). Barriers to international supply chain management in Iranian flower industry. Management Science Letters, 5(4), 363-368.

Riasi, A. (2015). Competitive Advantages of Shadow Banking Industry: An Analysis using Porter Diamond Model. Business Management and Strategy, 6(2), 15-27.

Rogalski, R. J., \& Tinic, S. M. (1986). The January Size Effect: Anomaly or Risk Mismeasurement ?, Financial Analysis Journal, 42(6), 63-70.

Schwarcz, S. L. (2012). Regulating Shadow Banking. Review of Banking and Financial Law, 31(1).

Shieh C. P. (2011) Fundamentals of corporate finance, Taipei: BestWise

Siegel, J. J. (1994), Stocks for the Long Run: A Guide to Selecting Markets for Long-term Growth. Burr Ridge, Illinois: Irwin Professional Publishing.

Unique Business Weekly (2014). http://paper.udn.com/udnpaper/POE0054/269625/web/

Yang, C. H. (2007). "The research of investment strategy analysis in Taiwan stock market-The comparison of value investment and growth investment." Taiwan, National Sun Yat-sen University.

Yang, T. Z., \& Yang, Y. T. (2015), Are There any Regular Variations in the Taiwan Stock Market: A Case Study of Taiwan Stock Exchange Capitalization Weighted Stock Index (TAIEX), Accounting and Finance Research, 4(1), 172-179.

\section{(c) $\mathbf{E Y}$}

This work is licensed under a Creative Commons Attribution 3.0 License. 